\title{
The Grinding Simulation Analysis of Rake Face of Ball End Mill's Circumference Blade
}

\author{
Li Shuai \\ College of Mechanical \& Electrical Engineering \\ Zaozhuang University \\ Zaozhuang, China; \\ Lishuai66@163.com
}

\begin{abstract}
The ball end mill, as an important tool to process the complex three-dimensional curved surface, is helpful to achieve high efficiency and high precision machining when was used with nc machine tool, which is highly demanded in the manufacturing factory. Based on the grinding principle of ball end mill, a mathematical model of rake face of circumference blade is established. A grinding process of rake face of circumference blade is simulated on the solidworks platform, which gets an ideal blade-shaped curve. Through the analysis of simulation results, the distribution law of rake angle of circumference blade's rake face is obtained, and it provides the basis for the optimization of grinding parameters in practical processing.
\end{abstract}

Keywords-Ball End Mill; Circumference Blade; Rake Face; Rake Angle; Solidworks

\section{INTRODUCTION}

Ball end mills are widely used in the machinery manufacturing industry, and they are an important tool of three-dimensional curved surface finish, which are mainly applied to the aviation \& aerospace, automobile, mould and other fields. At abroad, six-axis linkage machine tools are mainly adopted for manufacturing ball end mills, and the process is relatively complex, and the grinding cost is high[1]. Researchers adopt the four-axis linkage grinding method proposed by He Lin from Guizhou University, and through software simulation, the relatively reasonable blade-shaped curve is obtained, which demonstrates the validity of the previously established mathematical model and the rational distribution of rake angle. With a high accuracy and a short design cycle, the established simulation system greatly improves the efficiency and quality of ball end mill's design.

\section{THE GRINDING PRINCIPLE OF CIRCUMFERENCE BLADE'S RAKE FACE}

Ball end mill is composed of ball and handle. The cutting blade distributed in the handle is circumference blade, and the grinding principle of circumference blade's rake face is the same as that of spiral groove of grinding twist drill. When the grinding wheel conducts the spiral motion relative to mill workblank, the part of the circumference of the arc length where grinding wheel and mill workblank contact would form a spiral groove on the work piece[2]. In the process of ball end mill manufacturing, ball blade and circumstance blade are processed in turn at a time, and therefore after grinding the ball blade, the grinding wheel conducts the spiral motion relative to the work piece, and the envelope surface of grinding wheel bus motion is rake face of circumference blade. The relative motion relationship and position relationship of the grinding wheel and mill workblank that process the circumference blade's spiral groove are as shown in Figure 1.

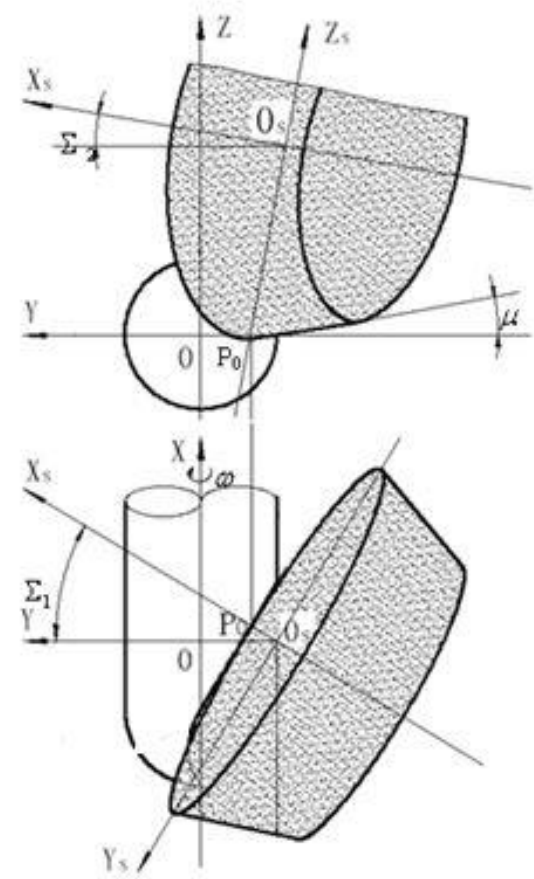

Figure 1. The position relationship of the grinding wheel and mill workblank of grinding the circumference blade's rake face

After the formation of ball blade's rake face, point $\mathrm{B}$ reaches point $\mathrm{Be}$ (Figure 2), which makes the formed bus $\mathrm{BC}$ arrive at the position as shown in Figure 3. $\mathrm{BC}$ turns into $\mathrm{BeCe}$, and the outside cone bus of the grinding wheel still works as the formed bus. On the one hand, the ball end mill still rotates around its axis; on the other hand it makes an axis motion, and the circumstance blade's helicoid formed is rake face of circumference blade [3]. 

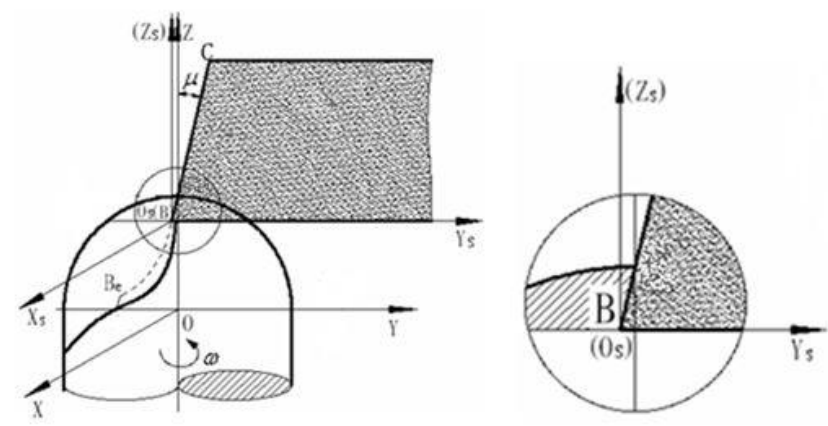

Figure 2. The transition from ball blade's rake face to circumference blade's rake face

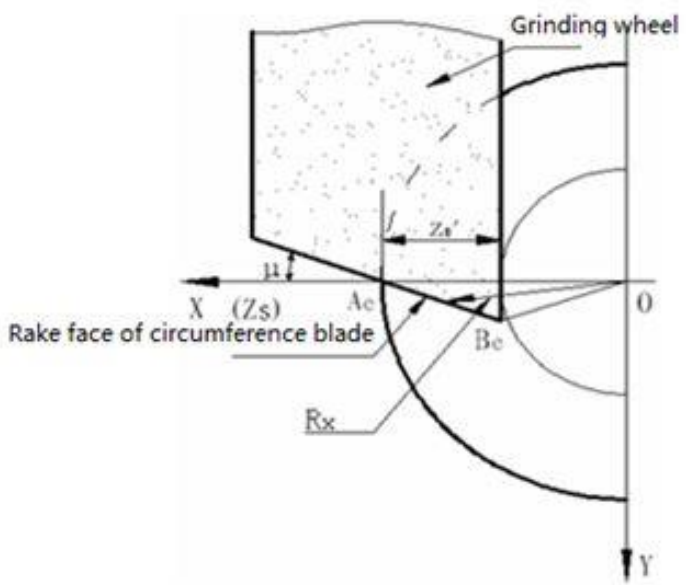

Figure 3. The mathematical model of circumference blade' s rake face

Rake face of circumference blade belongs to orthogonal helical, and the equation of rake face of circumference blade can be represented as:

(1)

$$
\left\{\begin{array}{l}
X=R_{X} \cos \omega \\
Y=R_{X} \sin \omega \\
Z=\frac{P_{z}}{2 \pi} \omega
\end{array}\right\}
$$

In the formula: $\mathrm{R}_{\mathrm{X}}$-radius of any point on the rake face of circumference blade, the calculation formula of $R_{X}$ is:

$$
R_{x}=\sqrt{X^{2}+(X-R)^{2} \tan ^{2} \mu}
$$

$\mu$ is the angle formed between the grinding wheel's bus and the grinding wheel's axis, that is the half taper of the cone grinding wheel.

\section{THE ESTABLISHMENT OF THE SIMULATION PRocessing System OF CIRCUMSTANCE Blade’' S RAKE FACE}

By making use of the entity modeling functions of the Solidworks software, this paper realizes the grinding simulation of rake face of ball end mill's circumference blade. First, researchers use the API function of Solidworks to draw a model sectional drawing; and then, use the rotation command to establish entity models of ball end mill's workblank and grinding wheel; and finally, researchers use VB programming language to replace the size parameters with variables, so that researchers can generate models automatically by the control of the variables to realize the parametric design of mill workblank and grinding wheel[4], which could be used in the follow-up programs. The equation of ball blade rake face in preliminary studies is:

$$
\left(\begin{array}{c}
\Delta X \\
\Delta Y \\
\Delta Z
\end{array}\right)=\left(\begin{array}{c}
X_{C_{0}} \\
Y_{C_{0}} \\
Z_{C_{0}}
\end{array}\right)-\left(\begin{array}{c}
X_{S 0} \\
Y_{S 0} \\
Z_{S 0}
\end{array}\right)=\left(\begin{array}{c}
R(1-\cos \theta)+R_{S} \cos a(1-\cos u) \\
R_{S}(\sin v-\sin a)-(R-c) \sin \theta \sin \omega \\
(R-c) \sin \theta \cos \omega+R_{S} \sin a \cos u
\end{array}\right)(3)
$$

According to the position relationship formed by rake face of circumference blade and ball blade, the entities of mill workblank and grinding wheel are adopted; and then researchers use the program to control the motion and deflection of the grinding wheel; through Boolean difference operation between the entities, the excision process of the entity of mill workblank is realized by the entity of the grinding wheel, which forms the rake face of circumference blade. The simulation results are shown in Figure 4.

In the process of grinding and machining for the rake face of the ball blade, the big circle of the grinding wheel is tangent with the curve at the bottom of spiral groove in the rake face of the ball blade, and the circular spiral groove on the milling cutter handle is grinded according to the way of normal spiral groove. The simulation results in Figure 5 shows that, the rake face of circular blade connected smoothly with the rake face of the ball blade, which improves the stability of the ball end mill in the cutting process. As it's shown in Figure 6, the ball blade is the reasonable s-shaped curve, crossing the central axis of the milling cutter with a smooth transition, so as to ensure good machining quality, cutting performance and chip removal ability of the milling cutter.

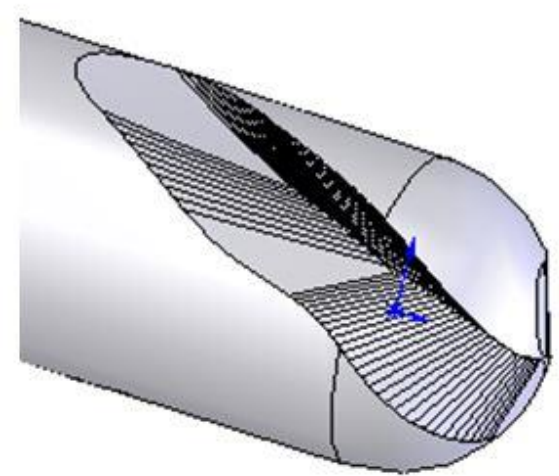

Figure 4. The simulation results figure of circumstance blade' $\mathrm{s}$ rake face 


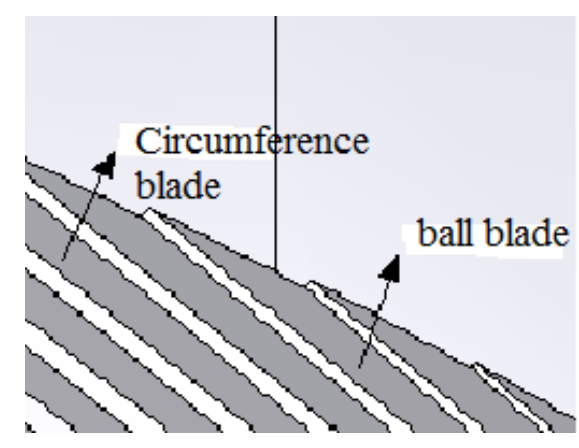

Figure 5. the connection between circular blade and the ball

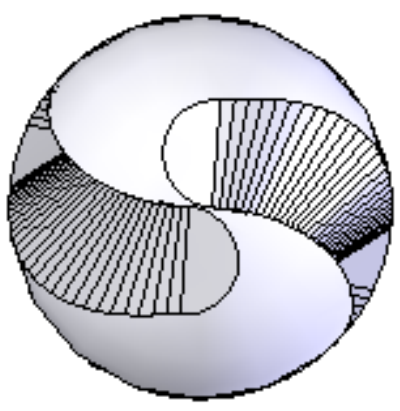

Figure 6. S-shaped ball milling

\section{THE Distribution OF RAKE ANGLE OF CIRCUMFERENCE BLADE`s RAKE FACE}

The size of rake angle determines the sharpness degree and intensity of cutting blade, and it has an important influence on the cutting process. By increasing the rake angle of the cutting tool can reduce the chip deformation, the cutting force, the cutting heat and the cutting power consumption, and therefore it can improve the durability of the cutting tool[5]; but the increase of rake angle can reduce wedge angle, and it decreases the blade strength on the other hand, which may cause tipping easily, so the durability of the cutting tool would decrease due to a big rake angle[6,7].

Rake face of circumference blade belongs to the helicoids[8]. When measuring the corresponding rake angle of any point on the circumstance blade, a section is made as perpendicular to the axis $\mathrm{X}$ and through this point[9]. Make a ligature by connecting the point on the circumstance blade and the center of the circle. And the included angle made by this ligature and the rake face projection is the rake angle, as shown in Figure 7.
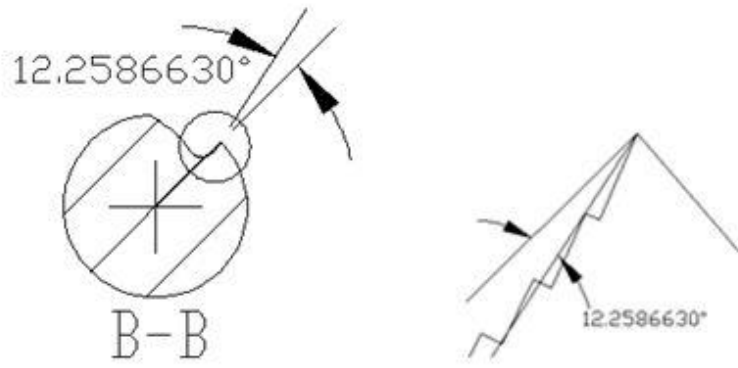

Figure 7. The rake angle of circumference blade' s rake face
Use the program to divide the circumstance blade for eight times, and the measurement process is shown in Figure 8. Table I shows the measurement results when in different positions.

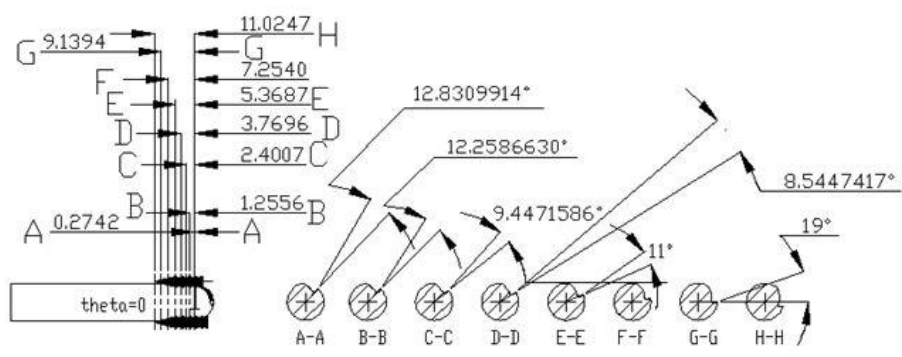

Figure 8. The measurement drawing of rake angle of circumference blade' $s$ rake face ${ }^{[10]}$

TABLE I. The MEASUREMENT Results of CircumFERENCE BLADE’'S RAKE ANGLE

\begin{tabular}{|c|c|c|}
\hline Number & Position $\boldsymbol{X}(\mathrm{mm})$ & Rake Angle \\
\hline 1 & 0.27 & $12.8^{\circ}$ \\
\hline 2 & 1.26 & $12.3^{\circ}$ \\
\hline 3 & 2.40 & $9.4^{\circ}$ \\
\hline 4 & 3.77 & $8.5^{\circ}$ \\
\hline 5 & 5.37 & $11.0^{\circ}$ \\
\hline 6 & 7.25 & $19.0^{\circ}$ \\
\hline 7 & 9.14 & $19.0^{\circ}$ \\
\hline 8 & 11.02 & $19.0^{\circ}$ \\
\hline
\end{tabular}

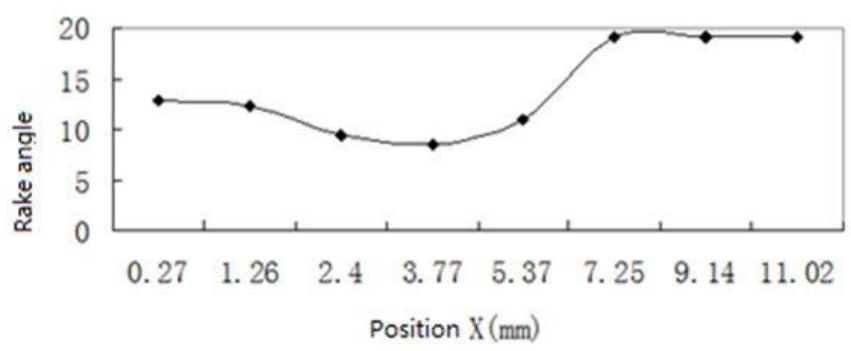

Figure 9. The distribution diagram of rake angles

\section{RAKE ANGLE DistRIBUtion OF THE RAKE FACE OF THE BALL BLADE}

The ball blade curve can be achieved when the rake face of the ball blade crossing with hemispherical surface, and the reference surface is changed due to the changes of normal vector of each point on the ball blade. Researchers define $\theta$ as the included angle between the connection line from any point to the ball center and $\mathrm{X}$ axis Angle (as shown in Figure 10), the distribution range of $\theta$ is $0^{\circ} \sim 90^{\circ}$ from the top of ball to the ball blade and circumference blade; $\partial$ is the included angle between the connection line from any point on the ball blade to the center of the ball and $\mathrm{Z}$ axis (Figure 11). 


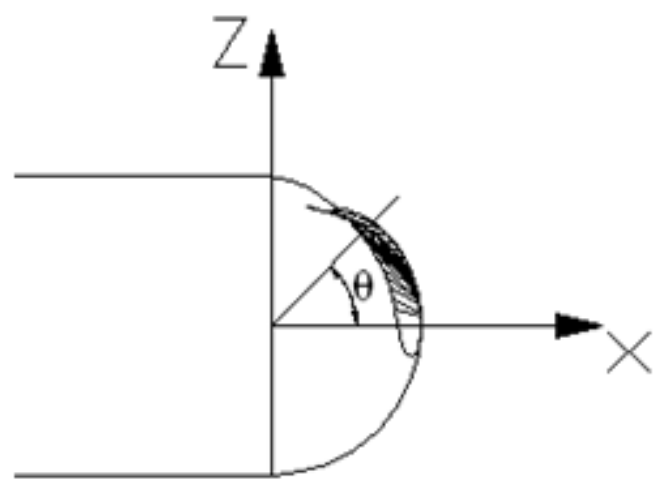

Figure 10. angle $\theta$ of the ball blade

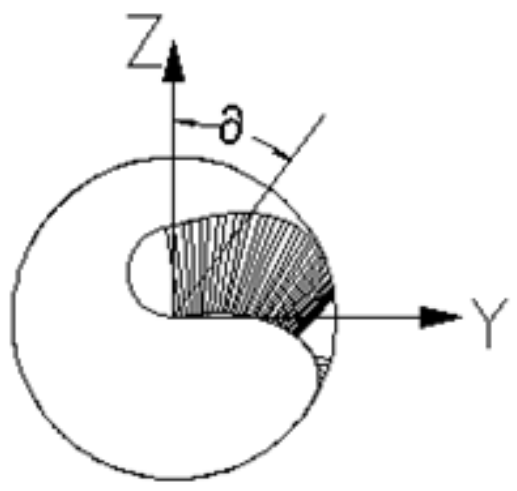

Figure 11. Corner $\partial$

The section which has one point on the ball blade, keeping vertical with its ball blade curve and passing the center of the ball head, needed to be measured. On the section, the included angle between the connection line from the points of the ball blade to the ball center and projection of the rake face is $b$. Researchers can get the distribution of the rake angles on the ball blade based on the anterior from changed $\theta$ (Figure 12). It can be seen that the rake angle distribute quite reasonably: the rake angles of the rake face of the ball blade are the larger ones, with the maximum as $32^{\circ}$ and the minimum as $12^{\circ}$, which distribute like that first increases then decreases from the top of the ball to the outer edge, that is smaller close to the top of the ball blade, bigger in the middle, then smaller near the circumference blade.

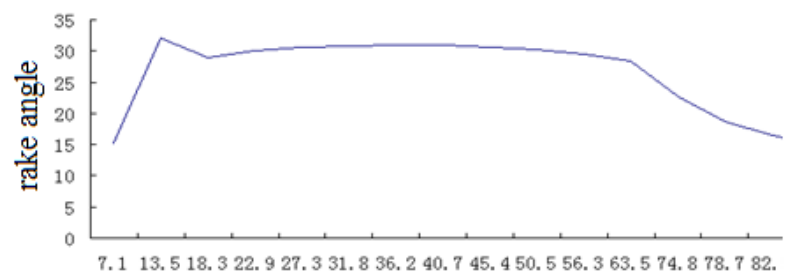

Figure 12. the distribution of the ball blade angle-rake angle

\section{CONCLUSIONS}

Machining simulation system can simulate the grinding process of the rake face of the ball end mill better, and the motion relationship proposed in the early stage[11] can continuously grind the rake face of the ball blade and circumference blade, which verifies the validity of the mathematical model; the rake face of the ball blade continuous transit with that of circumference blade, and the blade curve of the ball is S-shaped; the distribution of the rake face of circumference blade in distributed in a reasonable way with a maximum as $19^{\circ}$. The rake face of ball blade is distributed in a reasonable way with a maximum of $32^{\circ}$.

It can be seen from Figure 9 that the rake angle of circumference blade's rake face is a positive rake angle, which is relatively big, and its distribution is presented as "big-small-big"; that is, the rake angles close to the ball blade are relatively big, the angles in the middle are relatively small; with the increase in their distance to ball blade, rake angle becomes bigger till it remains the same.

\section{REFERENCES}

[1] Bing Yin Ren, Yu Yong Yang, "The Geometrical Models of the Design and 2-axis NC Machining of a Helical End-mill with Constant Pitch," Journal of Materials Processing Technology. 2011(115):265 270.

[2] Shi Lin, "The Research of Cylindrical Ball End Mill," Master thesis of Guizhou University, 1996, 6.I. S. Jacobs and C. P. Bean, "Fine particles, thin films and exchange anisotropy," in Magnetism, vol. III, G. T. Rado and H. Suhl, Eds. New York: Academic, 1996, pp. 271-350.

[3] Hebiao, "Research on the Grinding Processing of the New type of Ball End Mill," Master thesis of Guizhou University, 2005, 6.

[4] Solidworks Corporation. Solidworks 2005 API help.2015.

[5] Zhu Mengzhou, “Mechanical Engineers Handbook (second edition)," Mechanical industry publishing house, 2013.

[6] Ren Bingyin, Tang Yuyong, "The Geometric Modeling Theory and Its Application in the Nc Machining," Journal of Harbin Industrial University press, 2000, 1.

[7] Shi Peilin, Wangwei, Tang Yuyong, "Research on the Maths Model in the Ball End Mill Manufacturing, "Journal of mechanical engineering, 1994 (5): $55 \sim 59$.

[8] He Lin, Lishuai, etc, "Grinding simulation of the Rake Face of the Ball End Mill," Journal of mechanical design and manufacturing, 2009 (2) : $250 \sim 251$.

[9] Lishuai, "The Secondary Development and Parametric Design of SolidWorks," Journal of Zaozhuang College, 2010 (2) : $79 \sim 82$.

[10] Xia Wen-sheng, "Effects of Wheel Wear on the Manufacturing Errors of Ball-Nose End Milling Cutter," Modular Machine Tool \&Automatic Manufacturing Technique,2013(1): $39 \sim 41$.

[11] Xia Wen-sheng, "Effects of Wheel Wear on the Grinding Errors of Ball-Nose End Milling Cutter, " Machinery Design \& Mufacture,2013(5): $177 \sim 179$. 